\title{
Enhancing the First-Year University Experience: linking university orientation and engagement strategies to student connectivity and capability
}

\author{
STEPHEN LARMAR \& ANN INGAMELLS \\ School of Human Services and Social Work, \\ Griffith University, Brisbane, Australia
}

\begin{abstract}
Over the past decade in Australia there has been an increasing focus in higher education on identifying cogent approaches for assisting first-year university students in their transition into the university setting. In recent years, an emerging body of literature has given emphasis to the efficacy of a range of strategies for engaging first-year undergraduate students. This article reports on a range of effective school-based university orientation and engagement activities that have been informed by the current body of knowledge on student engagement in higher education. Discussion gives emphasis to the impacts of a range of strategies on the early learning environment experiences of first-year students within the School of Human Services and Social Work at Griffith University, Australia. Attention is also drawn to some of the implications for best practice in the orientation and engagement of first-year students at the levels of the institution, academics and students. Finally, the article identifies how the school-based initiated strategies suggest a broad set of possibilities for engagement and change.
\end{abstract}

\section{Introduction: the changing face of higher education in Australia}

In the last decade, Australian universities have experienced a shift in focus from elite to mass education (Nunan, 1999). Given that the number of students entering higher education has risen by $10 \%$ in the last decade, multiple challenges exist for universities interested in retaining positive outcomes for all students (Harris \& Palmer, 1995). This growth represents not only an increase in diversity amongst student populations, but also a need for universities to respond innovatively in order to meet the changing needs of this emergent and ever changing student body profile (McKenzie \& Schweitzer, 2001). These very real challenges, in concert with growing economic constraints for Australian universities, have engendered an increasingly competitive 'performance culture' that has had serious ramifications for higher education institutions, academics and students.

These changes in higher education, both within the Australian context and internationally, have generated a significant body of research that is focused on the first-year student experience (Longden, 2006). One way of approaching improvement in student learning is to conceptualise students as moving along a continuum from disengagement to engagement (Bryson \& Hand, 2007). Factors that epitomise engagement are many and interrelated. However, the importance of student satisfaction and its subsequent impact on retention and achievement constitutes a cogent argument (Lowe \& Cook, 2003). Such a model realises not only the importance of the role of teaching staff in fostering engagement (Rickinson \& Rutherford, 1996; Tinto, 1998; Bryson \& Hand, 2007), but also the importance of the social and cultural aspects of university life (Thomas, 
2002; Wilcox et al, 2005). The significance and impact of various aspects of the current student culture and engagement have been reinforced in a broad empirical analysis of these issues (Krause et al, 2005).

Academics working within the current climate are experiencing the fallout of decreased institutional, faculty and school-based funding. Demands of the changing work culture for academics based largely upon a struggling university economy include reduction in administrative support, allocation of larger class sizes, increasing teaching loads and pressures to be 'researchactive'. The exertion of such pressures is giving rise to a performative culture that has serious implications for academics working in the field who are committed to the transformative role of higher education.

The shifting economic and socio-political climate within higher education is also giving rise to a transforming student culture. The massification of education within the university sector has seen an increasingly diverse student population comprising students from varying social and cultural backgrounds (McInnes \& James, 1995; McKenzie \& Schweitzer, 2001). This diversified population of students is impacting upon commencing student expectations as well as conceptual and practical approaches to learning and teaching to meet consumer demands (Longden, 2006). In particular, pedagogical trends such as the emerging 'infotainment' approach, which serves to align with contemporary student consumer culture, are of particular concern to academics committed to the facilitation of transformative experiences of learning (Ryan, 2007).

\section{Student Engagement: predictors of success}

As a result of the shifting culture of higher education both nationally and internationally and the ensuing diversification of the student population, increasing attention has been drawn to the most effective strategies for engaging students. Recent research has identified a number of key predictors of success that serve to enhance the first-year university experience.

Naturally, student engagement can only be promoted in the context of an overarching institutional commitment (Tinto, 2002). Students are more likely to participate in academic life when steps are taken by university staff to actively engage them (Ahlfeldt et al, 2005). The more students participate and become involved in social and academic activities at university, the more likely they are to persist with their studies (Tinto, 1998). Lowe \& Cook (2003, p. 75) assert that 'intrusive, proactive strategies' of academic support delivered by universities early in the students' first year may prevent them from experiencing feelings of confusion and failure that lead to disengagement. Lowe \& Cook (2003) emphasise that those most at risk of such disengagement are students who struggle academically, and thus academic ability is a significant factor to consider in the retention and engagement of first-year university students.

It is not only academic ability, however, that correlates with engagement, but also the student's level of preparedness for university (Ozga \& Sukhnandan, 1998). As well as the availability of appropriate academic support at the transition stage, Rickinson \& Rutherford (1995) have identified the main factor in influencing student withdrawal/retention rates is the degree to which students feel prepared, both academically and emotionally, for the transition to university. Higher grades in secondary school predict higher grades at university (McKenzie \& Schweitzer, 2001) and study habits learned at school continue through the first year of university (Cook \& Leckey, 1999). It is worth noting that approximately two-thirds of students report that their final years at high school did not adequately prepare them for university life (Krause et al, 2005), and this may explain why $39 \%$ of students reported they were 'struggling' with their workload (Lowe \& Cook, 2003) and why approximately one-third of students 'drop out' (Clark \& Ramsay, 1990). It is clear that while high school does affect post-secondary outcomes and academic preparation (Clark \& Ramsay, 1990; Engberg \& Wolniak, 2010), the difference in the number of students who report that their final years at high school did not adequately prepare them for university (two-thirds) and the lower proportion of only one-third of students who actually 'drop out' suggests that variables beyond the student's high school experience can influence engagement. Thus, the need for early intervention programs in a student's first year of university that target a range of variables is paramount (Clark \& Ramsay, 1990; Tinto, 1998; Lowe \& Cook, 2003; Krause et al, 2005). 
The nature of relationships impacting upon students within the university context is another factor that influences their engagement. For example, the level at which students are capable and prepared for higher education can be influenced by university staff interaction and engagement (McGivney, 1996). In fact, the situation for students who struggle academically can be exacerbated by a lack of staff understanding (Lowe \& Cook, 2003). University staff who take strategic steps to encourage a deeper level of learning and engagement with students are able to prevent students from feeling a sense of alienation in higher education (Mann, 2001). Students who feel they can identify with their university's 'institutional habits' or cultural practices feel represented and included by their university and consequently engage more with all aspects of university life. Engagement can be promoted by staff through the fostering of positive attitudes and relationships with students, inclusive teaching and learning strategies, collaboration between staff and students, and a diversity of social spaces to cater for students in a way that reflects an implicit understanding and embracing of their individuality and various needs. All these strategies are vital in creating a milieu where students can 'be themselves' within the university environment (Thomas, 2002). The need to accommodate the various backgrounds of student groups and promote a positive student culture highlights the fact that it is not only staff-student relationships which are of significance in the process of transition, but also relationships amongst students themselves that promote engagement (Krause et al, 2005). Research indicates that making compatible friends is essential to student retention. Friendship formation can serve to provide the support necessary to buffer stressful situations experienced within the university context (Wilcox et al, 2005). Further, a sense of belonging contributes to better learning outcomes and increased retention (Kember et al, 2001), and participation in a learning community is positively correlated to engagement, outcomes and overall satisfaction with higher education.

However, it is not only community that fosters student engagement, but also positive forms of communication. As Mann (2005) argues, fostering a sense of community can be problematic and a greater focus is needed on treating learning communities as a communicative event that encourages engagement through supportive dialogue. Overall, it is recognised that the social dimension of learning is important (Weiner, 1985; Gerdes \& Mallinckrodt, 1994). Students become engaged when they are given an opportunity to forge appropriate links at university. Universities that act upon this knowledge to create a friendly and supportive environment for students generally perform above benchmark standards and maintain higher retention rates than those institutions who fail to implement such an approach (Yorke \& Thomas, 2003).

Inherent student factors also play a significant role in promoting engagement in learning. For example, student motivation and self-efficacy are important variables related to levels of engagement with university study (Lecompte et al, 1983; Ramsden, 2003). Regression analysis performed by Lent et al (1987) showed self-efficacy to be the most significant factor in predicting retention and academic performance. First-year students who attribute negative academic events to specific, unreliable, external causes generally receive higher grades than those who attribute negative events to stable internal causes (Peterson \& Barrett, 1987), while students with motivation and an internal locus of control typically respond more positively to university (Fazey \& Fazey, 2001). In short, students who take responsibility for their actions and are motivated to succeed will be more likely to engage with the university context.

Two further factors are considered significant in regard to university student retention and engagement. First is the maintenance of a healthy study/life balance, including paid work (McInnes et al, 2000; McInnes \& Hartley, 2002; McInnes, 2003), and second is social support beyond the university environment (Gerdes \& Mallinckrodt, 1994). In terms of student life balance, research indicates that there has been a significant rise in the number of full-time students in paid employment (Krause et al, 2005). Clearly, this impacts upon the student's ability to strike the right balance between the demands of study and the need to earn an adequate income. It is therefore not surprising to note that the average household wage of students who withdraw from university is lower than those who continue to pursue their studies. Thus, family income is another significant factor affecting ongoing engagement (Pantages \& Creedon, 1975). As indicated, the variable of social support beyond the university, including support for students from family and, in particular, parents, is another significant factor in promoting higher levels of engagement (Clark \& Ramsay, 1990). 
In summary, the literature identifies a range of factors that promote student engagement, which include: an overarching institutional commitment to student retention and engagement, academic ability, university preparedness, the fostering of positive partnerships between university staff and students, student motivation and self-efficacy, a sense of connectedness with university peers, the maintenance of a healthy study/life balance including paid work and social support beyond the university environment.

\section{School-Based Strategies to Enhance Engagement}

Given the current climate, universities, schools and faculties at a national level in Australia are emphasising a commitment to the engagement of first-year students. Over the last five years, Griffith University's School of Human Services and Social Work (HSV) has developed a range of approaches that have served to enhance the first-year experience. A series of frameworks, focused on institution-wide student retention and enhancement, have been developed that have received the long-term support of senior administration, i.e. the Deputy Vice Chancellor (Academic). Activities and directions as to how to improve the first-year experience, and thus improve retention rates across the institution, were informed by a large-scale, systematic, institution-based survey. The key outcomes of these activities have included the development and implementation of a First Year Advisor (FYA) role and the implementation of a school-based first-year community engagement activity called Common Time, for which Griffith University received recognition in a national university award in 2002.

Established in Australia in 1975, Griffith University is now one of the largest multi-campus higher education institutions in Australia, with 37,000 students and academic staff from 122 countries. The university emphasises an interdisciplinary approach to learning and teaching, and each of Griffith's five campuses are diverse in the programs they offer. The four broad organisational groups at Griffith include Business, Health, Arts, Education and Law (including Queensland College of Arts and Queensland Conservatorium of Music), and Science, Environment, Engineering and Technology (SEET). Each of these organisational groups cater to distinct cohorts of students with varying needs and issues. Strategies to encourage effective engagement of first-year students are therefore tailored to the distinctive make-up of the various student groups in order to ensure that the unique needs of each group are addressed. The following section outlines a number of cogent school-initiated strategies that have served to enhance the firstyear experience for human services and social work students which are informed by the literature around first-year student engagement.

\section{HSV Orientation Program}

In the last two years, the HSV has developed an increased focus on school-based activities to enhance the orientation experience of students in their transition to university. Data derived from a university-wide evaluation measure, the Starting@Griffith Experience of Orientation questionnaire, provided feedback to assist HSV staff involved in the development of orientation experiences in the refinement of the school orientation program. This process has assisted the school in the development of a two-day, school-specific orientation program that has enhanced students' experiences in their early engagement with the HSV. The HSV orientation program gives emphasis to connecting key first-year and administration staff with students as well as connecting the first-year cohort with one another. The program includes:

- an introductory lecture and tutorial to familiarise students with the key modes of learning embedded in the school's undergraduate degrees;

- information sessions focusing on course and program enrolments;

- sessions orientating students to specific university-wide and school-based supportive infrastructures to help students in their first-year studies;

- course information sessions presented by HSV first-year course conveners;

- get-to-know-you activities that serve to establish an initial sense of community within the cohort; and 
- a question and answer forum to assist students with any early problems they may encounter at the starting point in their introduction to the HSV.

The orientation program is facilitated by the HSV FYA in collaboration with key school-based firstyear and administration staff.

\section{The First Year Advisor}

In 2005, as part of Griffith University’s commitment to enhancing the first-year experience, an institution-wide initiative was established that involved the creation of the FYA role (Burnett $\&$ Larmar, 2008). A FYA was appointed in every school at Griffith at the commencement of 2005. The FYA is a full-time academic member of staff working within a specific school located in the seven faculties across the university. The FYA's key responsibilities include the facilitation of the orientation experience for students within their respective schools, as well as general responsibilities focusing around the academic and pastoral oversight of first-year students across the academic year. In most instances, FYAs at Griffith work to a specific workload formula that includes reduced teaching and/or research activity in order to focus on first-year teaching and learning experiences.

\section{Common Time}

Common Time is a school-based first-year activity designed to provide students with social and academic support within a flexible learning environment in order to assist their transition into university and their integration into the human services and social work programs. The Common Time activity was developed by the HSV in 2002 and, since its inception, has been adopted by other schools within Griffith University (Fowler \& Zimitat, 2008). As part of the Common Time program, first-year students meet with key first-year staff, including first-year course conveners and the FYA, for approximately two hours each week throughout the academic year as a means of focusing on first-year teaching and learning issues. Students' skills and knowledge in areas such as essay writing, oral presentations, information skills and professional development are enhanced through a mixture of structured and informal academic and professional sessions, which include guest speakers from the human services and social work fields. A significant emphasis of the Common Time experience centres on students developing a sense of community with their peers and key staff. This is achieved through the facilitation of student study groups and peer networks developed within the Common Time experience, in concert with regular interfacing with course conveners and the FYA.

\section{Student Mentoring}

The literature gives clear support to the use of mentoring as a means of assisting first-year students in their transition to university (Crisp \& Cruz, 2009). For the last two years, the HSV has embedded a mentoring program into the first-year experience in order to provide additional support to students. The program involves matching first-year students with second-, third-, fourth-year and postgraduate HSV students, who meet on a regular basis (at least once each week at the commencement of the academic year) to provide ongoing academic and personal support. Mentors receive training in the mentoring process and are overseen by a school-based mentor program coordinator throughout the first semester to assist in the ongoing facilitation of the program. The program is currently being evaluated to determine its effectiveness. However, anecdotal evidence focusing on students' perceptions of the program's influence would indicate that the HSV mentoring program is highly effective in assisting students in their transition into the school and broader university system. 
English Support

A further initiative developed within the HSV is the school-based English support program. A growing population of students entering the HSV are those who speak English as a second language (ESL). The majority of ESL students experience significant challenges in their academic and social adjustment. In order to assist students from ESL backgrounds, in 2006 the school developed the HSV English support program, a strategy that provides weekly support for ESL students. Students meet with an experienced tutor who facilitates weekly sessions that focus on written and oral assessments specific to the courses within the HSV first-year program. The English support tutor liaises with first-year conveners and the FYA to tailor the support program to meet the needs of the student group. While this strategy has not been formally evaluated, the majority of students who have accessed the program have experienced academic improvements across the courses they have undertaken.

\section{Method}

In order to determine the efficacy of the HSV approach to the orientation and engagement of firstyear students, and to inform the ongoing review and design of the first-year learning environment, evaluation data were derived from three sources. The first set of data was taken from two university-administered surveys comparing data across the 2006 and 2007 academic years, respectively. Both surveys were administered online between weeks five and eight of the first semester of study for all first-year students enrolled in programs at Griffith University. For both surveys, the participation rate was $36.3 \%(n=78)$ of the first-year cohort.

The items for both surveys were generated based on existing research and were also informed by knowledge of Griffith University campus life and orientation. The survey items included multiple-choice questions (for example: Which statement applies to you? - [a] I had about the right amount of information about my degree/program when arriving at Griffith, etc.) and statements that required students to indicate their level of agreement on a summated scale (for example: I know the names of key staff in my degree program -1 . Strongly disagree, etc.).

The first survey, the Starting@Griffith Experience of Orientation questionnaire, summarised commencing students' perceptions and experiences of orientation at Griffith University in 2007. The data captured within this instrument included student attendance and duration of attendance at orientation, appropriateness of information provided to students during orientation, experience of enrolment, perceived effectiveness and experience of orientation, opportunities for relationship building, students' awareness of staff and academic culture, and students' knowledge of support services and amenities.

The second Starting@Griffith survey was administered in conjunction with the first measure and explored commencing students' perceptions of their early experiences (i.e. the first four to six weeks) at Griffith University. This included the level to which students felt a sense of capability, purpose, connection (with staff, other students and community) and resourcefulness (helpful systems, key staff and university/life balance), their perceptions of academic engagement (for example, good teaching, clear goals, intellectual stimulation) and their overall satisfaction with the university. The two surveys also elicited demographic data and information about students' academic area, method of entry into university and the nature of potential employment outside of the university context.

A subsequent review of the survey instrument conducted at the end of 2008 involved consulting academic and student support staff and conducting statistical analyses to ensure the reliability and validity of the instrument. This resulted in a restructured instrument and the development of three key scores:

- Score 1. Program engagement. This score comprises six subscores: 1.1 Staff-student relationships; 1.2 Good teaching; 1.3 Sense of connection; 1.4 Sense of capability; 1.5 Sense of purpose; and 1.6 Overall satisfaction. Each subscore results from three items in which students rate their level of agreement on a five-point Likert scale.

- Score 2. Interaction with staff and students. This score results from six items which evaluate the quality of interaction and relationships with staff, peers and senior students. 
- Score 3. Effectiveness of orientation. This score results from four items which evaluate the organisation and perceived value of orientation activities and information.

The survey also includes Likert items to evaluate enrolment, information provision and knowledge of key support services, along with some open questions on those aspects that are most and least appreciated about enrolment, orientation and chosen degree programs.

The third and final set of data were taken from a school-based survey administered in week eight of semester one, 2007, developed to determine student perceptions about the Common Time strategy. The response rate for this survey was $31.33 \%(n=73)$.[1]

\section{Results}

\section{Starting@Griffith Experience of Orientation Data}

The overall results obtained from the Starting@Griffith Experience of Orientation survey indicate that improvements were gained in 2007 around students' perceptions of their orientation experience compared with data from 2006. The following provides a summary of the most significant findings.

Student engagement. The results indicating student engagement in the $2007 \mathrm{HSV}$ orientation week program were mixed. Approximately $28 \%$ of the first-year cohort attended all orientation activities, with $55 \%$ of the entire cohort attending a selection of the orientation program activities.

Information acquisition. In terms of information acquisition, $75 \%$ of students reported that the information offered provided the detail necessary to assist student orientation into the school.

Organisation. With regard to organisation, $79 \%(66 \%$ in 2006$)$ of students perceived that the orientation was well organised; $91 \%$ ( $83 \%$ in 2006) acknowledged that they would recommend the orientation experience for future students; and $75 \%(52 \%$ in 2006$)$ of students indicated that the program prepared them well for the beginning of the semester.

Connectivity. In terms of student perceptions around relationship-building opportunities throughout the orientation program, the results were mixed. Of the entire cohort, $69 \%(67 \%$ in 2007$)$ indicated that they felt there was sufficient opportunity to interact with staff in the school; $96 \%(85 \%$ in 2006$)$ acknowledged that there was opportunity to interact with peers; and 59\% (48\% in 2006) indicated that there was access to student mentors.

Knowledge of university staff and services. In the area of student knowledge relating to key staff in the school, support services offered within the university and campus amenities, the results were mixed: $88 \%$ ( $86 \%$ in 2006$)$ of students indicated that they knew the school's FYA and $81 \%(67 \%$ in 2006) acknowledged that they were familiar with key staff in the school. In terms of students' knowledge of support services, the responses were generally favourable and gains were made in comparison to student perceptions drawn from the 2006 data. Students' knowledge of campus amenities had also improved based on the 2006 responses. This data would suggest that the information offered in the 2007 orientation served to better orientate students in terms of key staff and services offered within the school and broader university.

\section{Starting@Griffith Perceptions of the Early Learning Environment Data}

In terms of student perceptions of the early learning environment within the HSV, the findings from the Starting@Griffith survey suggest that positive gains were identified in student responses in 2007 compared with 2006 responses. The sections outlined below delineate the key findings that emerged from the survey.

Disciplinary engagement. In the area of disciplinary engagement, students' perceptions were generally positive. Staff teaching practices rated highly. In terms of communication of learning 
goals and expectations, the results were mixed: $77 \%$ (75\% in 2006) of students indicated that staff made it clear what they expected from students. In the area of intellectual stimulation, the results were also relatively high, with the majority of students agreeing that their initial experiences of study in the degree program were intellectually stimulating.

Sense of capability. In terms of student capability, the results indicated that improvements had been made. Compared with the 2006 data, students indicated less desire for additional academic support and reported that guidance on how to approach their first assignment was sufficient. On items measuring students' academic efficacy, gains were also reported: $66 \%(53 \%$ in 2006$)$ of students strongly agreed that they felt optimistic about being successful in their first semester of study; $55 \%$ (44\% in 2006) indicated that they felt confident of achieving good results; and $58 \%$ (47\% in 2006) reported that they expected to do well in their first semester.

Sense of purpose. In terms of students' sense of purpose in embarking upon their studies within the school, the results were promising and showed similar trends to those derived from the 2006 data. On all items within this domain, students generally indicated that they had a clear sense of purpose in embarking on their studies within the HSV.

Sense of connectedness. Students' perceptions concerning their connection with staff were generally positive, which would appear to indicate that staff engagement during weekly lectures and the Common Time sessions are having a positive effect on staff-student relationships. In terms of students' perceptions relating to their sense of community, the results were also promising: $78 \%$ $(76 \%$ in 2006$)$ of students indicated that they felt they were fitting in well at a university level and $76 \%(52 \%$ in 2006) strongly agreed that they felt included as part of the school community. These responses suggest that existing community-building strategies at a school level are showing some effectiveness.

Sense of resourcefulness. On measures relating to student perceptions of their sense of resourcefulness, the results were mixed. Items focusing on helpful systems indicated that $38.6 \%$ (47\% in 2006) of students strongly agreed that there were effective procedures in place to help students solve problems; $85.7 \%$ (75.6\% in 2006) reported that it was made clear to them what a student could do when faced with a problem; and $73 \%(63 \%$ in 2007$)$ indicated that students are readily able to get the advice or assistance they need. On items measuring students' awareness of key staff, the results were mixed. Overall, $81 \%(67 \%$ in 2006) of students were aware of key staff in the school. It was positive to note that $88 \%(86 \%$ in 2006$)$ of students knew the FYA. In terms of students' perceptions relating to their life-university interface, only $54 \%(41 \%$ in 2006$)$ of students agreed or strongly agreed that they were coping well with the workload; $66 \%$ (65\% in 2006) expressed some concern about getting behind in their studies; and $78 \%$ ( $73 \%$ in 2006 ) indicated that they were finding it challenging to find time to study given other commitments.

Overall satisfaction. The reports relating to students' overall satisfaction were promising: $79 \%$ ( $75 \%$ in 2006) of students indicated that they were satisfied with their experiences of university so far; $83 \%(80 \%$ in 2006$)$ indicated that at the time point the survey was completed, their experience of university was worthwhile; and $77 \%$ ( $71 \%$ in 2006) reported that they were enjoying their studies at Griffith.

\section{HSV Common Time Evaluation Data}

A 25-item survey was administered in week seven of the first semester of study to determine student perceptions about the effectiveness of Common Time. Appendix 1 provides a summary of the results, which indicate that the Common Time strategy provides a cogent framework to effectively engage students in their studies and in their academic community. 


\section{Discussion}

The data derived from the Starting@Griffith surveys and the Common Time questionnaire would appear to indicate that the HSV approach to the orientation and engagement of first-year students is effective. In particular, students found the orientation program to be well organised and that it assisted them in integrating positively into the school and university culture. Orientation activities helped students to connect with key staff within the school and identify specific supportive infrastructures at both a school and institutional level. In terms of student experiences of the early learning environment, the results would indicate that student perceptions were also positive. Students generally reported that constructive connections were facilitated within the first-year community. Experiences such as Common Time served to develop positive connections with key first-year staff as well as establish student networks to provide additional support for learning. Such initiatives also influenced student confidence in engaging with the learning environment. In short, the evaluation of the HSV approach to the orientation and engagement of first-year students supports Tinto's (2002) emphasis on the importance of institutional commitment. Ahlfeldt et al's (2005) research describing positive outcomes in terms of students being more likely to participate in academic life when staff actively engage them is also supported in this evaluation. In addition, this study provides further evidence to support Tinto's (1998) assertions regarding the positive relationship between student involvement in social and academic activities at university and persistence with their studies.

The outcome data from the present study also affirmed research by Rickinson \& Rutherford (1996) and Ozga \& Sukhnandan (1998), who identified that while academic ability is a significant factor in engagement, a student's level of preparedness for university is even more important, particularly at the transition stage. The data indicated that the students' levels of preparedness in entering the HSV context had a significant part to play in their successful transition and adjustment. Further, the results also highlighted that students felt further prepared through participation in activities such as Common Time.

Despite the weight of evidence that the HSV approach to the orientation and engagement of first-year students is effective, there are a number of implications which significantly impact upon current practices in higher education at the levels of the institution, academics and students that require some attention. Although Griffith University has demonstrated a significant commitment to first-year transition experiences, it is important to recognise that such a commitment involves an allocation of financial and human resources that may be constraining for higher education institutions. Further, the investment given to such initiatives may affect the distribution of resources to other university infrastructures, resulting in problems associated with underresourcing in particular areas.

While the strategies outlined here seem to have elicited promising outcomes for first-year students, the cost to the academic staff involved in the facilitation of such strategies cannot be overestimated. The HSV staff group have given intentional consideration to the allocation of key staff involved in the first-year experience to assist in the development and implementation of the first-year orientation and engagement program. This consideration has had significant ramifications for staff across the school, particularly in circumstances where specific academics have had to undertake an increased workload to shoulder the efforts of the first-year conveners and FYA. Further, a significant proportion of school-based funds are also allocated to the first-year experience, which impacts upon the general distribution of resources for other key school-based teaching and learning and research activities.

Although the impacts of the HSV strategies have been positive, there are still implications for students and learning. The majority of the strategies employed by the HSV require initiative on the part of the student to fully engage with such support. Strategies including the HSV orientation and Common Time programs are heavily reliant on student participation. For individuals at greater risk of disengagement, such strategies may not be effective if the student is reticent to fully engage in his/ her program of study. 


\section{Limitations}

In terms of the present study, a number of limitations were identified. First, the confines of the research are limited to the HSV context. A generalisation of findings is therefore limited to university contexts that resemble the composition of the HSV at Griffith University. Second, the findings provide a general overview of student perceptions relating to their orientation and engagement experiences. More in-depth data gathering and analysis are necessary to determine findings that are more specific in nature. Finally, this research intentionally focused on school-based approaches and their impacts upon student transitional experiences. The evaluation of such approaches was limited to school-based strategies and did not consider institution-wide processes that may be of merit.

\section{Future Research}

There are a number of areas of future research that would assist in extending the body of knowledge around university student transition. Future investigations need to give consideration to more generic approaches to student engagement and the implications of their application to varying contexts. Studies investigating how specific approaches serve to ameliorate identified risk factors in at-risk students would serve to extend knowledge around the effectiveness of orientation and engagement strategies and their impacts on at-risk populations. An increased focus on 'the student voice' is also necessary to understand the best practices for meaningfully engaging first-year students, particularly in a climate where technological advancements are significant. Finally, further research is necessary to understand how schools, faculties and institutions can proactively utilise resources in an often economically strained institutional culture.

\section{Conclusion}

This article has presented an overview of a range of school-based strategies that have served to more effectively engage first-year human services and social work students. The discussion has centred upon a number of implications associated with institutions increasing their commitment to the orientation and engagement process. Finally, emphasis has been given to how findings from evaluation data associated with the HSV strategies identified have served to enhance the school's and university's understanding about best practice in the retention and engagement of first-year students.

\section{Note}

[1] For further information regarding the survey instruments outlined here, please contact the first author.

\section{References}

Ahlfeldt, S., Mehta, S. \& Sellnow, T. (2005) Measurement and Analysis of Student Engagement in University Classes Where Varying Levels of PBL Methods of Instruction Are in Use, Higher Education Research and Development, 24(1), 5-20. http:/ / dx.doi.org/10.1080/0729436052000318541

Bryson, C. \& Hand, L. (2007) The Role of Engagement in Inspiring Teaching and Learning, Innovations in Education and Teaching International, 44(4), 349-362. http:/ / dx.doi.org/10.1080/14703290701602748

Burnett, L. \& Larmar, S.A. (2008) Improving the First Year: the role of First Year Advisors (FYA). Paper presented at 21st International Conference on the First-year Experience, Dublin, 23-26 June.

Clark, E. \& Ramsay, W. (1990) Problems of Retention in Tertiary Education, Education Research and Perspectives, 17(2), 47-59.

Cook, A. \& Leckey, J. (1999) Do Expectations Meet Reality? A Survey of Changes in First-year Student Opinion, Journal of Further and Higher Education, 23(2), 157-171. http: / / dx.doi.org/ 10.1080/0309877990230201

Crisp, G. \& Cruz, I. (2009) Mentoring College Students: a critical review of the literature between 1990 and 2007, Research in Higher Education, 50(6), 525-545. http: / dx.doi.org/10.1007/s11162-009-9130-2 
Engberg, M. \& Wolniak, G. (2010) Examining the Effects of High School Contexts on Postsecondary Enrollment, Research in Higher Education, 51(2), 132-153. http: / dx.doi.org/10.1007/s11162-009-9150-y

Fazey, D. \& Fazey, J. (2001) The Potential for Autonomy in Learning: perceptions of competence, motivation and locus of control in first-year undergraduate students, Studies in Higher Education, 26(3), 345-361. http: / / dx.doi.org/10.1080/03075070120076309

Fowler, J. \& Zimitat, C. (2008) Common Time: embedding the concept of academic and social integration across cognate degree programmes, Innovations in Education and Teaching International, 45(1), 37-46. http: / / dx.doi.org/10.1080/14703290701757435

Gerdes, H. \& Mallinckrodt, B. (1994) Emotional, Social, and Academic Adjustment of College Students: a longitudinal study of retention, Journal of Counselling and Development, 72(3), 281-288.

Harris, N. \& Palmer, A. (1995) Doing More with Less: improving the quality of the first year experience on business undergraduate courses within the context of a diminishing resources base, Journal of Further \& Higher Education, 19(3), 63-73.

Kember, D., Lee, K. \& Li, N. (2001) Cultivating a Sense of Belonging in Part-time Students, International Journal of Lifelong Education, 20(4), 326-341. http: / / dx.doi.org/ 10.1080/02601370110048809

Krause, K.-L., Hartley, R., James, R. \& McInnes, C. (2005) The First Year Experience in Australian Universities: findings from a decade of national studies. Carlton: Centre for the Study of Higher Education, University of Melbourne.

Lecompte, D., Kaufman, L. \& Rouseeuw, P. (1983) Search for the Relationship between Interrupted University Attendance of First Year Students and Some Psychosocial Factors, Acta Psychiatrica Belgica, 83, 609-617.

Lent, R., Larkin, K. \& Brown, S. (1987) Comparison of Three Theoretically Derived Variables in Predicting Career and Academic Behavior: self-efficacy, interest congruence, and consequence thinking, Journal of Counseling Psychology, 34(3), 293-298. http:// dx.doi.org/10.1037/0022-0167.34.3.293

Longden, B. (2006) An Institutional Response to Changing Student Expectations and Their Impact on Retention Rates, Journal of Higher Education Policy and Management, 28(2), 173-187. http: / / dx.doi.org/10.1080/13600800600751044

Lowe, H. \& Cook, A. (2003) Mind the Gap: are students prepared for higher education? Journal of Further and Higher Education, 27(1), 53-76. http:/ / dx.doi.org/10.1080/03098770305629

Mann, S. (2001) Alternative Perspectives on the Student Experience: alienation and engagement, Studies in Higher Education, 26(1), 7-19. b http: / / dx.doi.org/10.1080/03075070020030689

Mann, S (2005) Alienation in the Learning Environment: a failure of community? Studies in Higher Education, 30(1), 43-55.

McGivney, V. (1996) Staying or Leaving the Course, Adults Learning, 7(6), 133-135.

McInnes, C. (2003) New Realities of the Student Experience: how should universities respond? Paper presented at European Association for Institutional Research, University of Limerick, Ireland, 24-27 August.

McInnes, C. \& Hartley, R. (2002) Managing Study and Work: the impact of full-time study and paid work on the undergraduate experience in Australian universities. Canberra: Department of Education, Science and Training.

McInnes, C. \& James, R. (1995) First Year on Campus: diversity in the initial experiences of Australian undergraduates. Canberra: Australian Government Publishing Service.

McInnes, C., James, R. \& Hartley, R. (2000) Trends in the First Year Experience in Australian Universities. Canberra: Australian Government Publishing Service.

McKenzie, K. \& Schweitzer, R. (2001) Who Succeeds at University? Factors Predicting Academic Performance in First Year Australian University Students, Higher Education Research and Development, 20(1), 21-33. http: / / dx.doi.org/10.1080/07924360120043621

Nunan, T. (1999) Graduate Qualities, Employment and Mass Higher Education. Paper delivered at the HERDSA (Higher Education Research \& Development Society of Australasia) Annual International conference, Melbourne, 12-15 July.

http:/ / www.herdsa.org.au/branches/vic/Cornerstones/pdf/Nunan.PDF (accessed 9 July 2010).

Ozga, J. \& Sukhnandan, L. (1998) Undergraduate Non-completion: developing an explanatory model, Higher Education, 52(3), 316-333. http:/ / dx.doi.org/10.1111/1468-2273.00100

Pantages, T.J. \& Creedon, C.F. (1975) Studies of College Attrition: 1950-1975, Review of Educational Research, 48(1), 49-101. 
Peterson, C. \& Barrett, L. (1987) Explanatory Style and Academic Performance among University Freshmen, Journal of Personality and Social Psychology, 53(3), 603-607. http: / / dx.doi.org/10.1037/ 0022-3514.53.3.603

Ramsden, P. (2003) Learning to Teach in Higher Education, 2nd edn. London: RoutledgeFalmer.

Rickinson, B. \& Rutherford, D. (1995) Increasing Undergraduate Student Retention Rates, British Journal of Guidance and Counselling, 23(2), 161-172.

Rickinson, B. \& Rutherford, D. (1996) Systematic Monitoring of the Adjustment to University of Undergraduates: a strategy for reducing withdrawal rates, British Journal of Guidance and Counselling, 24(2), 213-225.

Ryan, Y. (2007) Do You YouTube? Wanna Come to My Space? Musings on Narcissism in the 21st Century Student. Keynote Address presented at 10th Pacific Rim First Year in Higher Education Conference, Brisbane.

Thomas, L. (2002) Student Retention in Higher Education: the role of institutional habitus, Journal of Education Policy, 17(4), 423-442. http:/ / dx.doi.org/10.1080/02680930210140257

Tinto, V. (1998) Colleges as Communities: taking research on student persistence seriously, Review of Higher Education, 21(2), 167-177.

Tinto, V. (2002) Promoting Student Retention: lessons learned from the United States. Paper presented at 11th Annual Conference of the European Access Network, Prato, Italy, 19 June. http: / / www.sdcity.edu/support/SCS / DrTinto/LessonsLearned.pdf

Weiner, B. (1985) An Attributional Theory of Achievement Motivation and Emotion, Psychological Review, 92(4), 548-573. http:/ / dx.doi.org/10.1037/0033-295X.92.4.548

Wilcox, P., Winn, S. \& Fyvie-Gauld, M. (2005) 'It was nothing to do with the university, it was just the people': the role of social support in the first-year experience of higher education, Studies in Higher Education, 30(6), 707-722. http:/ / dx.doi.org/10.1080/03075070500340036

Yorke, M. \& Thomas, L. (2003) Improving the Retention of Students from Lower Socio-economic Groups, Journal of Higher Education Policy and Management, 25(1), 63-74. http: / / dx.doi.org/10.1080/13600800305737

\section{APPENDIX 1.}

Q1. Please indicate the extent to which you participated in the Common Time activities in the first six weeks of the semester.

$\begin{array}{lccccccc} & \text { Never (1) } & \text { Rarely (2) } & \text { Sometimes (3) } & \text { Often (4) } & \text { Always (5) } & \text { Total } & \text { Mean } \\ \text { No. } & 0 & 5 & 19 & 29 & 20 & 73 & 3.9 \\ \% & 0 & 7 & 26 & 40 & 27 & & \end{array}$

Q2. During the first six weeks of Common Time the information I received about my degree program was sufficient.

\begin{tabular}{|c|c|c|c|c|c|c|c|}
\hline & Strongly disagree & Disagree & Sometimes & Agree & Strongly agree & Total & Mean \\
\hline No. & 0 & 1 & 31 & 32 & 9 & \multirow[t]{2}{*}{73} & \multirow[t]{2}{*}{3.7} \\
\hline$\%$ & 0 & 1 & 41 & 44 & 12 & & \\
\hline \multicolumn{8}{|c|}{ Q3. Common Time experiences developed my awareness of key staff associated with my degree program. } \\
\hline & Strongly disagree & Disagree & Sometimes & Agree & Strongly agree & Total & Mean \\
\hline U. & 1 & 2 & 10 & 33 & 27 & \multirow[t]{2}{*}{73} & \multirow[t]{2}{*}{4.1} \\
\hline$\%$ & 1 & 3 & 14 & 45 & 37 & & \\
\hline
\end{tabular}

Q4. Through my experience of Common Time I was introduced to a range of services offered by the university (for example, computing and technology services, library services, etc.)

$\begin{array}{lccccccc} & \text { Strongly disagree } & \text { Disagree } & \text { Sometimes } & \text { Agree } & \text { Strongly agree } & \text { Total } & \text { Mean } \\ \text { No. } & 0 & 2 & 12 & 36 & 23 & 73 & 4.0 \\ \% & 0 & 3 & 16 & 49 & 32 & & \end{array}$

Q5. During Common Time expectations of teaching staff regarding my academic responsibilities in my degree program were made clear.

$\begin{array}{lccccccc} & \text { Strongly disagree } & \text { Disagree } & \text { Sometimes } & \text { Agree } & \text { Strongly agree } & \text { Total } & \text { Mean } \\ \text { No. } & 0 & 5 & 23 & 34 & 11 & 73 & 3.7 \\ \% & 0 & 7 & 32 & 47 & 15 & & \end{array}$

Q6. The activities during the first six weeks of Common Time prepared me well for my first semester of study.

$\begin{array}{lccccccc} & \text { Strongly disagree } & \text { Disagree } & \text { Sometimes } & \text { Agree } & \text { Strongly agree } & \text { Total } & \text { Mean } \\ \text { No. } & 1 & 7 & 23 & 34 & 8 & 73 & 3.6 \\ \% & 1 & 10 & 32 & 47 & 11 & & \end{array}$


Q7. Common Time provided a forum for students to establish a clear understanding of their study pathway relating to their degree program.

$\begin{array}{lccccccc} & \text { Strongly disagree } & \text { Disagree } & \text { Sometimes } & \text { Agree } & \text { Strongly agree } & \text { Total } & \text { Mean } \\ \text { No. } & 2 & 1 & 36 & 19 & 16 & 73 & 3.7 \\ \% & 3 & 1 & 49 & 26 & 21 & & \end{array}$

Q8. Overall, the Common Time sessions were well organised and provided a structure conducive to my learning needs.

$\begin{array}{lccccccc} & \text { Strongly disagree } & \text { Disagree } & \text { Sometimes } & \text { Agree } & \text { Strongly agree } & \text { Total } & \text { Mean } \\ \text { No. } & 0 & 13 & 24 & 23 & 13 & 73 & 3.5 \\ \% & 0 & 18 & 33 & 32 & 18 & & \end{array}$

Q9. Common Time provided an opportunity for me to interact with staff in my degree program.

$\begin{array}{lccccccc} & \text { Strongly disagree } & \text { Disagree } & \text { Sometimes } & \text { Agree } & \text { Strongly agree } & \text { Total } & \text { Mean } \\ \text { No. } & 0 & 5 & 20 & 25 & 22 & 72 & 3.9 \\ \% & 0 & 7 & 28 & 35 & 31 & & \end{array}$

Q10. Common Time provided an opportunity where students could express their opinions or concerns to staff in a supportive environment.

$\begin{array}{lccccccc} & \text { Strongly disagree } & \text { Disagree } & \text { Sometimes } & \text { Agree } & \text { Strongly agree } & \text { Total } & \text { Mean } \\ \text { No. } & 0 & 4 & 17 & 34 & 18 & 73 & 3.9 \\ \% & 0 & 5 & 23 & 47 & 25 & & \end{array}$

Q11. During Common Time staff seemed to be committed in their support for students.

$\begin{array}{lccccccc} & \text { Strongly disagree } & \text { Disagree } & \text { Sometimes } & \text { Agree } & \text { Strongly agree } & \text { Total } & \text { Mean } \\ \text { No. } & 1 & 1 & 18 & 35 & 18 & 73 & 3.7 \\ \% & 1 & 1 & 25 & 48 & 25 & & \end{array}$

Q12. Common Time staff actively checked that students understood staff/university expectations.

\begin{tabular}{|c|c|c|c|c|c|c|}
\hline Strongly disagree & Disagree & Sometimes & Agree & Strongly agree & Total & Mean \\
\hline No. & 6 & 25 & 31 & 11 & \multirow[t]{2}{*}{73} & \multirow[t]{2}{*}{3.6} \\
\hline 0 & 8 & 34 & 42 & 15 & & \\
\hline \multicolumn{7}{|c|}{ Q13. Common Time provided a forum for staff to outline their expectations of students. } \\
\hline Strongly disagree & Disagree & Sometimes & Agree & Strongly agree & Total & Mean \\
\hline 0 & 5 & 17 & 37 & 14 & \multirow{2}{*}{73} & 3.8 \\
\hline 0 & 7 & 23 & 51 & 19 & & \\
\hline
\end{tabular}

Q14. Overall, the interaction with staff during Common Time was positive.

$\begin{array}{lccccccc} & \text { Strongly disagree } & \text { Disagree } & \text { Sometimes } & \text { Agree } & \text { Strongly agree } & \text { Total } & \text { Mean } \\ \text { No. } & 0 & 0 & 16 & 40 & 17 & 73 & 4.0 \\ \% & 0 & 0 & 22 & 55 & 23 & & \end{array}$

Q15. Common Time provided an opportunity for me to interact with students in my degree program.

$\begin{array}{lccccccc} & \text { Strongly disagree } & \text { Disagree } & \text { Sometimes } & \text { Agree } & \text { Strongly agree } & \text { Total } & \text { Mean } \\ \text { No. } & 0 & 3 & 23 & 32 & 14 & 72 & 3.8 \\ \% & 0 & 4 & 32 & 44 & 19 & & \end{array}$

Q16. Common Time has assisted in helping me to build meaningful networks with other students in my program of study.

$\begin{array}{lccccccc} & \text { Strongly disagree } & \text { Disagree } & \text { Sometimes } & \text { Agree } & \text { Strongly agree } & \text { Total } & \text { Mean } \\ \text { No. } & 2 & 6 & 31 & 24 & 10 & 73 & 3.5 \\ \% & 3 & 8 & 42 & 33 & 14 & & \end{array}$

Q17. Common Time has assisted in helping me to feel a part of the university culture.

$\begin{array}{lccccccc} & \text { Strongly disagree } & \text { Disagree } & \text { Sometimes } & \text { Agree } & \text { Strongly agree } & \text { Total } & \text { Mean } \\ \text { No. } & 0 & 4 & 35 & 22 & 12 & 73 & 3.6 \\ \% & 0 & 5 & 48 & 30 & 16 & & \end{array}$

Q18. I have found the first six weeks of the Common Time program has stimulated my thinking and enhanced my learning.

$\begin{array}{lccccccc} & \text { Strongly disagree } & \text { Disagree } & \text { Sometimes } & \text { Agree } & \text { Strongly agree } & \text { Total } & \text { Mean } \\ \text { No. } & 0 & 10 & 28 & 23 & 12 & 73 & 3.5 \\ \% & 0 & 14 & 38 & 32 & 16 & & \end{array}$

Q19. Common Time has assisted in giving me greater confidence in achieving better results in the first semester of my program of study.

$\begin{array}{lccccccc} & \text { Strongly disagree } & \text { Disagree } & \text { Sometimes } & \text { Agree } & \text { Strongly agree } & \text { Total } & \text { Mean } \\ \text { No. } & 0 & 7 & 32 & 27 & 7 & 73 & 3.5 \\ \% & 0 & 10 & 44 & 37 & 10 & & \end{array}$


Q20. Common Time has assisted in alleviating some of the initial concerns I held about my first semester of study at university.

\begin{tabular}{|c|c|c|c|c|c|c|c|}
\hline & Strongly disagree & Disagree & Sometimes & Agree & Strongly agree & Total & Mean \\
\hline No. & 1 & 2 & 23 & 40 & 7 & \multirow[t]{2}{*}{73} & \multirow{2}{*}{3.7} \\
\hline$\%$ & 1 & 3 & 32 & 55 & 10 & & \\
\hline \multicolumn{8}{|c|}{ Q21. Common Time has assisted in giving me a clearer sense of why I am attending university. } \\
\hline & Strongly disagree & Disagree & Sometimes & Agree & Strongly agree & Total & Mean \\
\hline No. & 1 & 9 & 35 & 19 & 8 & 72 & 3.3 \\
\hline$\%$ & 1 & 13 & 49 & 26 & 11 & & \\
\hline
\end{tabular}

Q22. At this point in time I am finding Common Time to be a valuable resource that assists me with my study program.

\begin{tabular}{|c|c|c|c|c|c|c|c|}
\hline & Strongly disagree & Disagree & Sometimes & Agree & Strongly agree & Total & Mean \\
\hline No. & 2 & 9 & 33 & 19 & 9 & \multirow[t]{2}{*}{72} & \multirow[t]{2}{*}{3.3} \\
\hline$\%$ & 3 & 13 & 46 & 26 & 13 & & \\
\hline \multicolumn{8}{|c|}{ Q23. I would recommend to next year's first-year students that they participate in Common Time. } \\
\hline & Strongly disagree & Disagree & Sometimes & Agree & Strongly agree & Total & Mean \\
\hline No. & 1 & 1 & 23 & 30 & 17 & 72 & 3.8 \\
\hline$\%$ & 1 & 1 & 32 & 42 & 24 & & \\
\hline
\end{tabular}

Q24. Overall, I have been very happy with the Common Time experience as a means of assisting me in my transition into university.

\begin{tabular}{lccccccc} 
& Strongly disagree & Disagree & Sometimes & Agree & Strongly agree & Total & Mean \\
No. & 1 & 6 & 21 & 27 & 16 & 71 & 3.7 \\
$\%$ & 1 & 8 & 30 & 38 & 23 & \\
\hline
\end{tabular}

Table AI. Common Time survey results.

STEPHEN LARMAR is a First Year Advisor and Senior Lecturer in the School of Human Services and Social Work at Griffith University, Logan Campus, Australia. Correspondence: Stephen Larmar, Griffith University, Logan Campus, Meadowbrook, Queensland 4131, Australia (s.larmar@griffith.edu.au).

ANN INGAMELLS is a senior lecturer in the School of Human Services and Social Work at Griffith University, Logan Campus, Australia. Correspondence: Ann Ingamells, Griffith University, Logan Campus, Meadowbrook, Queensland 4131, Australia (a.ingamells@griffith.edu.au). 